\title{
DESENVOLVIMENTO DE UM GENOSSENSOR NANOESTRUTURADO BASEADO EM POLIPIRROL, NANOPARTÍCULAS DE ÓXIDO DE ZINCO E QUITOSANA PARA A DETECÇÃO ELETROQUÍMICA DO ONCOGENE QUIMÉRICO BCR/ABL
}

\author{
M. R. SANTOS ${ }^{1}$, K. Y. P. S. AVELINO ${ }^{1,2}$, N. LUCENA-SILVA ${ }^{3}$, C. A. S. ANDRADE ${ }^{1,2}$ e \\ M. D. L. OLIVEIRA ${ }^{1,2}$ \\ ${ }^{1}$ Universidade Federal de Pernambuco, Centro de Biociências, Departamento de Bioquímica, \\ Laboratório de Biodispositivos Nanoestruturados \\ ${ }^{2}$ Universidade Federal de Pernambuco, Centro de Biociências, Programa de Pós-Graduação \\ em Inovação Terapêutica \\ ${ }^{3}$ Centro de Pesquisas Aggeu Magalhães \\ E-mail para contato: ana19.mary@gmail.com
}

RESUMO - O oncogene quimérico $B C R / A B L$, originado por uma mutação cromossômica, desencadeia a leucemia mielóide crônica. Algumas das técnicas de detecção molecular, como a reação em cadeia da polimerase (PCR) e a hibridação in situ fluorescente (FISH), são bastante utilizadas, porém, apresentam desvantagens como o alto custo e longo tempo de análise. Desta forma, o presente trabalho teve como objetivo desenvolver uma ferramenta alternativa de diagnóstico. Um biossensor eletroquímico baseado em polipirrol, nanopartículas de óxido de zinco ( $\mathrm{Nps} \mathrm{ZnO}$ ) e quitosana foi construído e testes com plasmídeos recombinantes contendo o oncogene foram realizados para verificação da sensibilidade e especificidade do sistema. Foi observado, a partir das técnicas eletroquímicas (voltametria cíclica - VC e espectroscopia de impedância eletroquímica - EIE), que a cada etapa de montagem do biossensor houve modificações nas propriedades condutoras e resistivas do sistema, indicando sua eficácia e capacidade de reconhecimento bioespecifico.

PALAVRAS-CHAVE: Biodispositivo. Diagnóstico. Leucemia.

\begin{abstract}
The chimeric oncogene BCR / ABL, caused by a chromosomal mutation, triggers chronic myeloid leukemia. Some of the molecular detection techniques, such as polymerase chain reaction (PCR) and fluorescence in situ hybridization (FISH), are widely used, however, they present disadvantages such as high cost and long time of analysis. Therefore, the present work had as objective to develop an alternative
\end{abstract}


diagnostic tool. An electrochemical biosensor based on polypyrrole, zinc oxide nanoparticles (ZnONps) and chitosan was constructed and tests with recombinant plasmids containing the oncogene were performed to verify the sensitivity and specificity of the system. Was observed, from the electrochemical techniques (cyclic voltammetry - CV and electrochemical impedance spectroscopy - EIS), that at each stage of biosensor assembly there were modifications in the conductive and resistive properties of the system, indicating its efficacy and ability to biospecific recognition.

KEYWORDS: Biodevice. Diagnosis. Leukemia.

\section{INTRODUÇÃO}

A leucemia mielóide crônica é uma neoplasia caracterizada pela presença de um cromossomo marcador, cromossomo Phyladelphia, o qual contém o oncogene quimérico $\mathrm{BCR} / \mathrm{ABL}$. Esse oncogene é responsável por codificar três isoformas da proteína tirosina quinase que desencadeiam a proliferação descontrolada e o bloqueio da apoptose em células progenitoras hematopoiéticas (FADER et al., 1999; MULLIGHAN et al., 2008). Sabendo-se disso, o diagnóstico precoce do oncogene quimérico BCR/ABL promove ao paciente com leucemia uma maior probabilidade de cura. A maioria das técnicas usuais para o diagnóstico molecular de leucemia apresentam limitações de custo e tempo, tais como a PCR e FISH. Tendo isto em vista, o desenvolvimento de biossensores eletroquímicos vêm ganhando espaço na área de diagnósticos clínicos por apresentarem alta sensibilidade, seletividade e resposta analítica rápida com baixo custo (SHARMA et al., 2012; ROVINA; SIDDIQUEE, 2016). Os biossensores são constituídos por uma camada biológica responsável por detectar o analito, ligada a um transdutor, que transforma o sinal da interação biomolecular em uma resposta quantificável; logo depois, esta resposta é amplificada em um processador eletrônico e convertida em gráficos (FRÍAS et al., 2015). Os tipos de biossensores variam de acordo com a camada biológica e o tipo de transdutor utilizado, um exemplo é o biossensor de DNA (genossensor) eletroquímico, que faz uso de segmentos de ácidos nucléicos como elemento de reconhecimento biológico e das técnicas eletroquímicas para mensuração de sinais analíticos (WANG; DAI, 2015). Diante da problemática acerca do diagnóstico molecular de leucemia, este trabalho teve como principal objetivo construir um biossensor de DNA para a detecção eletroquímica do oncogene quimérico BCR/ABL baseado em polipirrol, $\mathrm{NpsZnO}$ e quitosana. Em adição, a bioatividade do dispositivo nanoestruturado foi avaliada através de ensaios com amostras plasmidiais contendo o oncogene quimérico $\mathrm{BCR} / \mathrm{ABL}$. Em todas as etapas de estudo, as técnicas de VC e EIE atuaram como ferramentas para a caracterização eletroquímica.

\section{MATERIAIS E MÉTODOS}

Para a construção da plataforma nanoestruturada foram utilizados o polipirrol ( $98 \%$ de pureza), as NpsZnO ( $<50 \mathrm{~nm}$ e $97 \%$ de pureza) e a quitosana, que foram obtidos na Sigma Aldrich Co. (St Louis, USA), e uma sonda de DNA específica para o reconhecimento do oncogene quimérico BCR/ABL, fornecida pela Prof ${ }^{a}$. Dr ${ }^{\mathrm{a}}$. Norma Lucena Cavalcanti Licínio da Silva, pertencente ao Laboratório de Imunogenética do Centro de Pesquisas Aggeu 
Magalhães/Fiocruz (Recife, Brasil). O biossensor eletroquímico foi construído sobre um eletrodo de ouro, atuando como um eletrodo de trabalho, que junto a outros dois eletrodos, um eletrodo de referência e um eletrodo de contra-referência, foram imersos em uma célula eletroquímica contendo uma solução de ferro-ferricianeto de potássio usada como sonda redox. A célula eletroquímica foi mantida dentro de uma gaiola de Faraday e associada a um potenciostato Autolab PGSTAT 128N. As medidas de VC e EIE foram mensuradas através do programa NOVA 1.11 (Metrohm Autolab, The Netherlands). Os voltamogramas cíclicos foram obtidos em uma faixa de potencial de $-0,2 \mathrm{a}+0,7 \mathrm{~V}$ com velocidade de varredura de 50 mV.s ${ }^{-1}$ (AVELINO et al., 2014) e os espectros de impedância foram registrados em uma faixa de frequência de $100 \mathrm{mHz}$ a $100 \mathrm{KHz}$ com um potencial de amplitude alternada de $10 \mathrm{mV}$ (LUNA et al., 2015). Inicialmente, foi realizada a eletropolimerização do polipirrol sob uma faixa de potencial de $-0,4 \mathrm{a}+1,0 \mathrm{~V}$ com velocidade de varredura de $100 \mathrm{mV} \cdot \mathrm{s}^{-1}$, porém os eletrodos estavam imersos em $20 \mathrm{ml}$ de solução de $\mathrm{HCl}$ a $0,5 \mathrm{M}$ contendo $41,62 \mu \mathrm{L}$ de pirrol a $30 \mathrm{mM}$. Em seguida, a camada de NpsZnO e quitosana foi adicionada por meio do método de drop coating, utilizando-se $2 \mu 1$ de uma mistura de proporção $1 / 1$ contendo quitosana a $0,5 \%$ dissolvida em ácido acético a $1 \%$ e NpsZnO a $1 \mathrm{mg} / \mathrm{mL}$, e a imobilização da sonda de DNA foi efetuada com o auxílio do agente reticulante glutaraldeído a $0,5 \%$. Nesta etapa, foi acrescentado $1 \mu \mathrm{L}$ de glutaraldeído sobre a superfície do eletrodo de ouro modificado, deixando-se por $10 \mathrm{~min}$. Subsequentemente, $2 \mu \mathrm{L}$ da sonda de DNA foram adicionados, onde ficou por $15 \mathrm{~min}$ até o momento da leitura. É importante destacar que ao final do processo de imobilização da sonda de biorreconhecimento, o eletrodo foi imerso em uma solução de albumina sérica bovina (BSA) a 1\% para o bloqueio de sítios não específicos do biossensor. Por último, com o biodispositivo montado, foram realizados ensaios de biodetecção com amostras de plasmídeos recombinantes contendo o oncogene quimérico BCR/ABL. Todos os testes experimentais foram realizados em triplicatas a temperatura ambiente $\left(24^{\circ} \mathrm{C} \pm 1\right)$.

\section{RESULTADOS E DISCUSSÃO}

Os voltamogramas cíclicos para cada etapa de montagem do nanossistema podem ser visualizados na figura 1, onde pode-se perceber uma alteração na resposta eletroquímica do eletrodo de ouro após a deposição de cada camada. Pelo fato do polipirrol ser um polímero condutor (MAHMOUDIAN et al., 2011), houve um aumento nas correntes de pico anódica e catódica e, consequentemente, um aumento na área voltamétrica após o processo de eletropolimerização do pirrol. Ressalta-se que esta alta condutividade do polipirrol é importante para a obtenção de sistemas eletroquímicos com maiores sensibilidades (GERARD; CHAUBEY; MALHOTRA, 2002). Após a deposição sequencial de NpsZnO, quitosana, sonda de DNA e BSA sobre a superfície do eletrodo de trabalho, ocorreram diminuições sucessivas nas respostas amperométricas. Estes resultados indicam a formação adequada de cada camada auto-organizada, impedindo, de forma moderada, as reações redox na dupla camada elétrica. Foi verificado na figura 1B que as análises de EIE são coerentes com o estudo de VC, já que à medida que as substâncias foram adicionadas sobre o filme de polipirrol, verificou-se um aumento gradual nos valores de resistência à transferência de carga. Por meio destes resultados, constata-se que o biossensor eletroquímico foi construído de forma efetiva.

É pertinente salientar que, para que haja funcionalidade, estabilidade e reprodutibilidade no biossensor, o componente biológico tem que estar firmemente aderido ao transdutor e presente em uma quantidade significativa. Por estas razões, a presença das NpsZnO na plataforma biossensível é imprescindível para aumentar a área superficial e possibilitar a 
imobilização de um maior número de

sondas DNA, o que assegura um efetivo processo de biorreconhecimento (TERESHCHENKO et al., 2016). Em adição, o biopolímero quitosana fornece grupos amino funcionais que se ligam covalentemente às sondas de DNA, garantindo assim, sua imobilização química (ROVINA; SIDDIQUEE, 2016; ATES, 2013).

Figura 1 - Voltamogramas cíclicos (A) e espectros de impedância (B) para cada etapa de montagem do biossensor eletroquímico baseado em polipirrol, NpsZnO e quitosana.

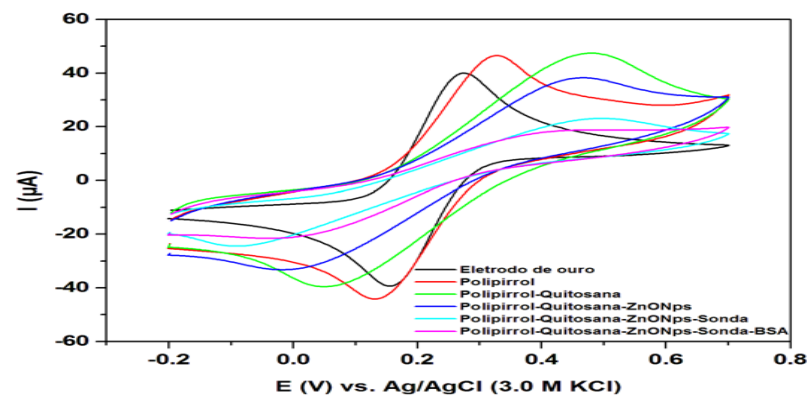

B

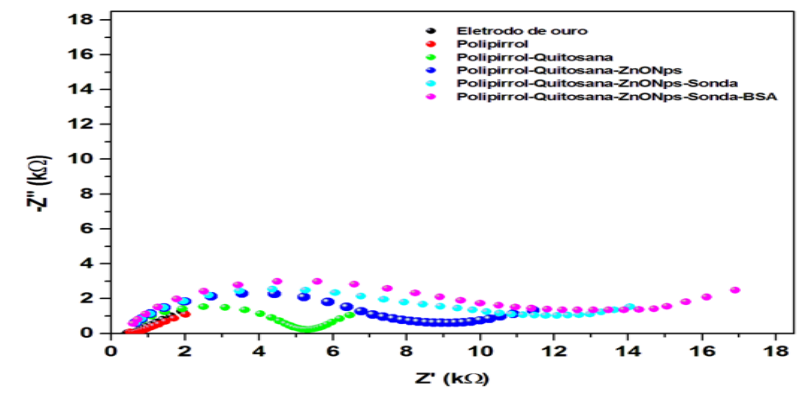

Após a montagem do biossensor de DNA, foi realizada a caracterização voltamétrica do processo de reconhecimento bioespecífico com plasmídeos recombinantes contendo o oncogene quimérico BCR/ABL em diferentes concentrações. Neste ensaio, pode-se observar uma diminuição das correntes de oxido-redução e uma diminuição das áreas voltamétricas (Figura 2), inferindo-se que houve a detecção do oncogene quimérico BCR/ABL no material biológico. Ademais, destaca-se que o biossensor proposto possui um limite de detecção de $138 \mathrm{aM}$, o que possibilita a identificação do oncogene quimérico BCR/ABL em níveis mínimos. Esta característica é essencial para a aplicação de biossensores em estudos de monitoramento oncogenético e diagnóstico de doença residual mínima.

Figura 2 - Caracterização voltamétrica do processo de reconhecimento bioespecífico do biossensor eletroquímico com plasmídeos recombinantes contendo o oncogene quimérico $\mathrm{BCR} / \mathrm{ABL}$ em variáveis concentrações

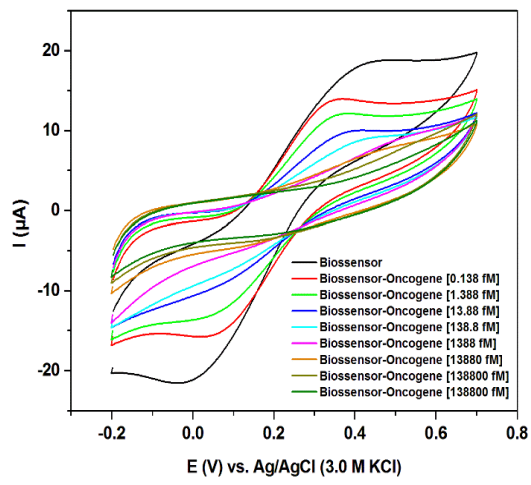




\section{CONCLUSÃO}

O diagnóstico precoce e o monitoramento dos níveis do oncogene quimérico BCR/ABL é de extrema importância para promoção da saúde de pacientes com leucemia mielóide crônica. Com base nos dados obtidos, conclui-se que o biossensor proposto neste trabalho é uma ferramenta analítica de alta especificidade e sensibilidade, capaz de detectar o oncogene quimérico BCR/ABL em concentrações mínimas (limite de detecção de $138 \mathrm{aM}$ ). Além disso, o dispositivo nanoestruturado é considerado um instrumento promissor para a realização de ensaios clínicos e laboratoriais, fornecendo respostas analíticas reprodutíveis com rápido tempo de análise e baixo custo.

\section{REFERÊNCIAS}

AVELINO, K.Y.P.S. et al. Biosensor based on hybrid nanocomposite and CramoLL lectin for detection of dengue glycoproteins in real samples. Synthetic Metals, v. 194, p. 102-108, 2014.

FADER, S. et al. The biology of chronic myeloid leukemia. The New England Journal of Medicine. v. 341, p. 164-172, 1999.

FRÍAS, I.A.M. et al. Trends in biosensors for HPV: identification and diagnosis. Journal of Sensors, v. 2015, p. 1-16, 2015.

GERARD, M.; CHAUBEY, A.; MALHOTRA, B.D. Application of conducting polymers to biosensors. Biosensors and Bioelectronics, v. 17, n. 5, p. 345-359, 2002.

LUNA, D.M.N. et al. Electrochemical immunosensor for dengue virus serotypes based on 4-mercaptobenzoic acid modified gold nanoparticles on self-assembled cysteine monolayers. Sensors and Actuators B: Chemical, v. 220, p. 565-572, 2015.

MAHMOUDIAN, M.R. et al. Electrochemical charactristics of coated steel with poly (Nmethyl pyrrole) synthesized in presence of $\mathrm{ZnO}$ nanoparticles. Thin solid films, v. 520, p. 258-265, 2011.

MULLIGHAN, C.G. et al. BCR-ABL1 lymphoblastic leukaemia is characterized by the deletion of Ikaros. Nature, v. 453, p. 110-114, 2008.

ROVINA, K.; SIDDIQUEE, S. Electrochemical sensor based rapid determination of melamine using ionic liquid/zinc oxide nanoparticles/chitosan/gold electrode. Food Control, v. 59, p. 801-808, 2016.

SHARMA, A. et al. Chitosan encapsulated quantum dots platform for leukemia detection. Biosensors and Bioelectronics, v. 38, p. 107-113, 2012.

TERESHCHENKO, A. et al. Optical biosensors based on $\mathrm{ZnO}$ nanostructures: advantages and perspectives. A review. Sensors and Actuators B: Chemical, v. 229, p. 664-677, 2016.

WANG, Z.; DAI, Z. Carbon nanomaterial-based electrochemical biosensors: an overview. Nanoscale, v. 7, n. 15, p. 6420-6431, 2015.

\section{AGRADECIMENTOS} pesquisa.

Agradecemos ao CNPQ, UFPE e Propesq pelo apoio financeiro e incentivo a 